\title{
Nonbinding Recommendations: The Relative Effects of Focal Points versus Uncertainty Reduction on Bargaining Outcomes
}

\author{
David L. Dickinson* \\ Dept. of Economics \\ Appalachian State University
}

\author{
Lynn Hunnicutt \\ Dept. of Economics \\ Pacific Lutheran University
}

\begin{abstract}
This paper focuses on the effects of nonbinding recommendations on bargaining outcomes. Recommendations are theorized to have two effects: they can create a focal point for final bargaining positions, and they can decrease outcome uncertainty should dispute persist. While the focal point effect may help lower dispute rates, the uncertainty reduction effect is predicted to do the opposite for risk-averse bargainers. Which of these effects dominates is of critical importance in the optimal design of alternative dispute resolution (ADR) procedures, which are becoming increasingly utilized to help resolve disputes in a variety of settings. We theoretically examine the effects of recommendations on the bargaining contract zone. Our theoretical framework, which allows bargainers' final positions to influence a binding outcome should negotiations fail, provides for a more stringent test of focal points than previously considered. We also present data from controlled laboratory bargaining experiments that are consistent with our model of recommendation effects. Recommendations are empirically shown to influence final bargaining positions and negotiated settlement values. Furthermore, dispute rates are significantly lower when one includes recommendations, even where the recommendation is completely ignored in final-stage arbitration. This highlights a potentially significant role for the use of nonbinding procedures, such as mediation, as a preliminary stage in developing more efficient ADR procedures.
\end{abstract}

JEL Key Words: Bargaining, Experiments, Dispute Resolution, Focal Points, Arbitration

JEL Codes: C78, C92, J52

*This research was supported by the National Science Foundation (Economics program grant \#0316414). Valuable comments were provided by seminar participants at GATE, the University of Alabama, and conference participants at the Economic Science Association meetings. The authors thank Yinghui Wang for research assistance. The authors also thank Kamalakar Thota, Jianlin Cheng, Lujun Zhang, Pablo F. Rego Barros, and Stacie Gomm for their work on the computerized bargaining application. 


\section{Introduction}

A significant institutional trend of the last 20-30 years has been the increased emphasis on alternative dispute resolution (ADR) programs, such as arbitration and mediation, to help resolve disputes. ADR programs currently operate in a wide variety of contexts that include, among others, union-management negotiations, commercial contract disputes, divorce negotiations, college campus conflict, and civil/community (neighborhood) disputes. Community mediation programs are estimated to have almost 20,000 active volunteer community mediators nationwide in programs that now receive over 97,000 annual case referrals. ${ }^{1}$ Though only available in about $15 \%$ of colleges, campus mediation programs experienced a ten-fold increase during the 1990s (from around 20 to over 200). ${ }^{2}$ Tort reform in several states has included implementing court-annexed ADR procedures prior to litigation in order to relieve pressure on the backlogged litigation system. Also, the Federal Mediation and Conciliation Services (FMCS) — an independent government agency created to promote labormanagement peace - has an annual mediation intake of nearly 40,000 cases and receives nearly 20,000 annual arbitration panel requests. ${ }^{3}$

In short, the volume of its use now makes ADR a significant institution in the U.S., not to mention elsewhere, and the trend towards increased ADR use appears persistent. Any improvements in ADR institutional design would significantly reduce dispute costs in the U.S. and promote improved bargaining relationships, which are likely to further reduce future dispute

\footnotetext{
${ }^{1}$ Statistics are from the National Association for Community Mediation (NAFCM), and are available at the NAFCM website at www.nafcm.org.

${ }^{2}$ Data reported can be found on www.campus-adr.org, funded in part by a grant from the federal Fund for the Improvement of Postsecondary Education (FIPSE).

${ }^{3}$ Data available in the annual reports available on the FMCS website at www.fmcs.org.
} 
rates. An examination of the key characteristics of different ADR procedures is necessary in order to design the most effective dispute settlement institutions.

An ADR procedure can be generally classified as binding (e.g., litigation or arbitration) or nonbinding (e.g., mediation). Binding procedures guarantee a settlement, but nonbinding procedures allow the bargainers to retain more control over the settlement, which increases bargainer satisfaction with the outcome. Some procedures are formal or informal hybrids where a nonbinding procedure is utilized initially, and then a binding procedure follows if needed. This is the case, for example, with court-annexed ADR that might compel the use of mediation prior to litigation. ${ }^{4}$ There is a general consensus that bargainers typically prefer mediation to binding arbitration or litigation, but it is unclear whether settlement rates are uniformly higher under mediation. In naturally occurring bargaining data, only the most serious disputes are handled with a binding procedure. The resultant sample selection implies that a simple examination of settlement rates from field data across various ADR procedures cannot identify the most effective ADR procedure for settling comparable disputes. Further, because it is often difficult to quantify the factors that make one dispute more serious than another, econometric tools designed to address sample selection are at a disadvantage.

This paper focuses on the use of nonbinding recommendations to improve binding dispute settlement procedures (e.g. arbitration, litigation, or legislation). Specifically, we ask whether recommendations can improve settlement rates and bargaining outcomes. A nonbinding recommendation has two potential effects on bargainers. First, a recommendation may serve as a

\footnotetext{
${ }^{4}$ For example, Wisconsin arbitrators for public sector labor disputes first mediate the cases, and they only use arbitration in the event that mediation fails (see Babcock and Taylor, 1996). Also, Hebdon (2001) notes that New York state public policy allows certain disputes to utilize a formal fact-finder recommendation, which is nonbinding, prior to implementation of a legislated (binding) settlement. As another example, many counties in Utah and North Carolina now require that divorce and custody cases be mediated before they proceed to trial.
} 
focal point, thereby improving the chance of voluntary settlement. On the other hand, a recommendation may reduce the uncertainty surrounding the likely outcome from litigation or arbitration. In this case recommendations may actually increase dispute rates for risk-averse bargainers who prefer settlement versus the uncertain lottery of arbitration (see Farber and Katz, 1979). Which of these two effects dominates is of critical importance in evaluating whether nonbinding ADR can improve the effectiveness of litigation or arbitration. Additionally, we consider whether bargaining positions are affected by the inclusion of recommendations, because final bargaining positions may affect the outcomes determined by arbitration, litigation, or legislation. We examine these issues theoretically, and we also present data from controlled laboratory bargaining experiments that generally support the hypothesized beneficial effects of recommendations: lower dispute rates and convergent final offers. Lower dispute rates reduce the need to invoke a binding settlement procedure, and convergent final offers lead to less variable (i.e., more acceptable) outcomes in the event that binding ADR is needed.

A separate strand of experimental economics research is starting to identify the potentially important role of "advice" from other players in affecting behavior and improving outcome efficiency (e.g., Schotter, 2003: Schotter and Sopher, 2002). These emerging studies of intergenerational games are innovative but quite distinct from our interests. The recommendations that we consider are not passed down from a previous generation of players, and our recommenders do not have a financial incentive in the bargainers' outcomes-in fact, we mechanize the implementation of recommendations as random draws from a settlement distribution. The recommendations we examine therefore come from a disinterested third-party, which is modeled after neutral ADR agents who have no authority to issue binding settlements. 
The potential benefits from a systematic use of recommendations in ADR procedures are significant given the ease with which any binding settlement procedure could be amended to allow for a preliminary nonbinding recommendation. In other words, we do not narrow our focus to testing one or two new ADR procedures, as has been done in previous research. Rather, our focus is on the use of recommendations that could be integrated more system-wide across a large variety of existing binding settlement procedures. If such nonbinding recommendations can increase voluntary settlement rates - generally considered a measure of ADR success - this could help minimize the costly use of litigation, binding arbitration, and legislatures in determining settlements. To the extent that voluntary settlements are considered more efficient than mandated settlements (see Crawford, 1979), this would also improve the efficiency of bargaining outcomes in many contexts.

\section{Theoretical Framework}

The model is an extension of Farber and Katz (1979) that incorporates a fact finder and also utilizes a "sophisticated" arbitrator similar to that used by Farber (1981). Consider two bargainers $B$ and $S$ engaged in zero-sum bargaining over one dollar (or any fixed amount of money). For simplicity, we will often refer to bargainer B (S) as the buyer (seller). Bargainer utility depends on risk preferences, $c$, and the fraction of the "pie" received:

$$
U_{S}=\frac{1-\exp \left(y c_{S}\right)}{1-\exp \left(c_{S}\right)} \quad \text { and } \quad U_{B}=\frac{1-\exp \left(z c_{b}\right)}{1-\exp \left(c_{b}\right)}
$$

where $y$ is the amount player $S$ receives, and $z=1-y$ is the amount that player $B$ receives. Utility increases in the fraction of the pie received, with $U(0)=0$ and $U(1)=1$. Risk preferences are 
defined solely by $-c_{i}$ for $i=b, s$, the Arrow-Pratt measure of absolute risk aversion (see Farber and Katz, 1979). As such, player $i$ is risk-averse (loving) when $c_{i}<(>) 0$.

Bargaining impasse is ultimately settled by a binding decision-maker we refer to as the arbitrator. Bargainers are uncertain about the exact settlement preferences, $D$, of the arbitrator, and this uncertainty is modeled by assuming that bargainers know the distribution function from which preferred settlements are drawn. Let $y_{i F}$ and $\sigma_{i}^{2}$, for $i=b, s$, be the bargainer's expectation of the mean and variance of the arbitrator's preference over the amount the seller receives. Farber and Katz (1979) examine the bargaining contract zone - the region of settlements both bargainers prefer, ex ante, over arbitration—assuming that the settlement is a random draw, $D$, from the distribution of the arbitrator's preferred settlements.

Dickinson and Hunnicutt (2005) show that a non-binding recommendation reduces the size of this contract zone both before and after the recommendation is given, under what they call "naïve" arbitration. Under naïve arbitration, the arbitrator does not place any weight on the bargainers' final offers in crafting a binding settlement. This is rather unrealistic, and the present paper considers a more realistic "sophisticated" arbitrator, whose decision rule is as follows. Suppose that a nonbinding recommendation, $R$, is given to the bargainers at some intermediate point prior to declaration of impasse. The recommendation (or suggestion) is nonbinding, but bargainers are aware that the arbitrator places a weight, $\gamma \in[0,1]$, on the recommendation relative to his own settlement preference when crafting the binding settlement. In addition, the sophisticated arbitrator weights the midpoint of the bargainers' final offers, $x_{b}$ and $x_{s}$, in making his settlement choice, $y_{s}$. Specifically, final settlement given to the seller is now

$$
y_{S}=(1-\delta) \cdot\left(\frac{x_{b}+x_{s}}{2}\right)+\delta \cdot[\gamma R+(1-\gamma) D]
$$


where $\delta=\frac{x_{s}-x_{b}}{S}$, and $\mathrm{S}$ is the size of the total bargaining range. This function for $\delta$ captures the intuition of Farber (1981) in that the arbitrator places increasingly more weight on the bargainers' final offers the more they converge (as $\delta$ approaches zero, the weight on the final offers approaches one). Alternatively, the farther apart are the final offers - in this case $\delta$ approaches 1 - the more the arbitrator ignores the final offers. The idea is that bargainers who are "close" to agreement ought to have a settlement that reflects their stated preferences (offers), while offers that diverge suggest that settlement is unlikely and final offers are less informative, which gives the arbitrator more leeway in imposing his own settlement preference.

This formulation allows us to consider cases where the recommendation is completely ignored $(\gamma=0)$, as well as cases where the arbitrator simply adopts the recommendation as the settlement $(\gamma=1)$. This latter case is less interesting given that $\gamma=1$ implies that all uncertainty is resolved once a recommendation is made. Henceforth, we maintain the assumption that $\gamma<1$. As long as some positive weight is placed on the recommendation (i.e., $0<\gamma<1$ ), then the uncertainty surrounding an arbitrated settlement is reduced. If uncertainty is important to encourage risk-averse bargainers to settle, then it follows that a recommendation may be counterproductive for voluntary settlement. On the other hand, if the recommendation serves as a focal point, then it may improve settlement rates even though it reduces outcome uncertainty.

The boundaries of the contract zone are defined by the certainty equivalent of each bargainer, or the minimum (maximum) amount that the seller (buyer) would be willing to accept (pay) to avoid the uncertainty of proceeding to arbitration. The literature refers to certainty equivalents alternatively as reservation values or threat points of the bargainers, and our theoretical framework assumes that final threat points (i.e., final offers) can be affected by 
recommendations. We show in the appendix that the contract zone, $\Delta$, of mutually acceptable settlement outcomes is given by

$$
\Delta=\delta \cdot(1-\gamma) \cdot\left(y_{b F}-y_{s F}\right)-\left[\frac{c_{b} \sigma_{b}^{2}+c_{s} \sigma_{s}^{2}}{2}\right] \cdot(1-\gamma)^{2} \cdot \delta^{2}
$$

This reduces to the Farber and Katz (1979) contract zone for the case where $\delta=1$ (the arbitrator ignores final offers) and $\gamma=0$ (the arbitrator ignores - or is unaware of - the recommendation).

\section{$\underline{3 \text { Focal Point Effects of Recommendations }}$}

We formalize the focal point hypothesis by assuming that bargainers' final offers are their initial threat points modified by the recommendation. Specifically, assume that

$$
x_{b}=\alpha R+(1-\alpha) \hat{x}_{b} \text { and } x_{s}=\beta R+(1-\beta) \hat{x}_{s}
$$

where $\hat{x}_{b}$ and $\hat{x}_{s}$ are the buyer's and seller's, respectively, exogenously given initial threat points, which represent their prior preferences regarding a settlement. ${ }^{5}$ In the extreme case, one might think of $\hat{x}_{b}$ as the minimum value of the bargaining range (the buyer prefers to pay as little as possible), and $\hat{x}_{s}$ as the maximum value of the bargaining range (the seller prefers to receive as much as possible), though $\hat{x}_{s}$ and $\hat{x}_{b}$ may be more moderate. If $R$ serves as a focal point then $\alpha, \beta>0$. It is possible to assume $\alpha$ and $\beta$ are functions of the recommendation, but for now we maintain the assumption that they are exogenously given, and represent the degree to which the recommendation influences the final offers. Also assume for simplicity that bargainers have common beliefs about the arbitrator's settlement preferences, $y_{b F}=y_{s F}$. In this

case, substituting (3) into (2), and taking into account that $\delta=\frac{x_{s}-x_{b}}{S}$, we have

\footnotetext{
${ }^{5}$ One might also assume a nonlinear specification for the equations in (3), but this unduly complicates the analysis.
} 


$$
\Delta=\left[\frac{-\left(c_{b} \sigma_{b}^{2}+c_{s} \sigma_{s}^{2}\right)}{2}\right] \cdot(1-\gamma)^{2} \cdot\left[\frac{\left(\hat{x}_{s}-\hat{x}_{b}\right)-\beta\left(\hat{x}_{s}-R\right)-\alpha\left(R-\hat{x}_{b}\right)}{S}\right]^{2}
$$

Assuming that bargainers are, on average risk averse, the first term in (4) is positive. ${ }^{6}$ This first term is just the Farber and Katz (1979) contract zone, which shows the contract zone increasing in the risk aversion of the bargainers.

The second and third terms in (4) capture the effects of the focal point and the sophisticated arbitrator on the contract zone. The second term is due to the arbitrator weighting the recommendation by $\gamma \in[0,1]$, with higher weights shrinking the contract zone, ceteris paribus. The last term in (4), call it $\mathrm{T}$, is due to the sophisticated arbitrator and is where focal points indirectly affect the contract zone. The size of the contract zone is increasing in T. As long as the numerator of this term is less than $S$, the total size of the bargaining range, then the term $\mathrm{T}$ shrinks the contract zone. More convergent final offers will therefore shrink the contract zone via the sophisticated arbitrator, and more convergent offers may occur for two reasons.

First, the preferences of the bargainers may be more moderate than they need be $\left(\hat{x}_{s}<\max\right.$ or $\hat{x}_{b}>$ min values of the bargaining range). Assuming no focal points $(\alpha=\beta=0)$, then $\mathrm{T}=\left[\frac{\left(\hat{x}_{s}-\hat{x}_{b}\right)}{S}\right]^{2}$ and so $\frac{\partial T}{\partial\left(\hat{x}_{s}-\hat{x}_{b}\right)}>0$. Secondly, the recommendation will moderate the bargainers' final positions if $\alpha=\beta>0$, but the location of the recommendation does not affect the size of the contract zone. To see this, rearrange and rewrite

\footnotetext{
${ }^{6} \mathrm{We}$ consider joint risk aversion a reasonable assumption in general. This assumption is supported by data in Holt and Laury (2002), who find that experimental subjects responding to non-hypothetical lottery questions are typically risk averse, even over "normal" laboratory payoffs. The assumption of risk aversion also seems realistic in application to real-world negotiations. Though risk preferences were not measured for our subjects, Dickinson (2005) reports results from experiments using the same general student subject pool, and he finds both Players A and
} 
$\mathrm{T}=\left[\frac{\left(\hat{x}_{s}-\hat{x}_{b}\right)-\left(\beta \hat{x}_{s}-\alpha \hat{x}_{b}\right)+R(\beta-\alpha)}{S}\right]^{2}=\left[\frac{\left(\hat{x}_{s}-\hat{x}_{b}\right)-\left(\beta \hat{x}_{s}-\alpha \hat{x}_{b}\right)}{S}\right]^{2}$ for $\alpha=\beta=0$. This makes it clear that the location of $\mathrm{R}$ does not affect the contract zone, because then $\left[\frac{\partial \Delta}{\partial R}\right]=0$. Also, if $\alpha=\beta=0$, then define $\varphi=\alpha=\beta$, and $\mathrm{T}=\left[\frac{\left(\hat{x}_{s}-\hat{x}_{b}\right)-\varphi\left(\hat{x}_{s}-\hat{x}_{b}\right)}{S}\right]^{2}=\left[\frac{\left(\hat{x}_{s}-\hat{x}_{b}\right)(1-\varphi)}{S}\right]^{2}$ and $\frac{\partial T}{\partial \varphi}=-2\left[\frac{\left(\hat{x}_{s}-\hat{x}_{b}\right)(1-\varphi)}{S}\right]\left(\frac{\left(\hat{x}_{s}-\hat{x}_{b}\right)}{S}\right)<0$, which implies $\left[\frac{\partial \Delta}{\partial \varphi}\right]<0$. In other words, the more the recommendation serves as a focal point to either bargainer, then the more it indirectly shrinks the contract zone via the sophisticated arbitrator.

It is also worth noting in (4) that both the size and location of the contract zone may be influenced by the recommendation. Because of the way that bargainer preferences are formulated, if recommendations are focal (i.e. $\alpha, \beta>0$ ), then a large recommendation increases final offers. This will raise the arbitrator's final settlement, since the midpoint between final offers (which is something the sophisticated arbitrator considers) is now larger, making bargainer certainty equivalents higher (see appendix). That is, holding the distance between final offers constant, higher recommendations shift the contract zone to the right. $^{7}$

The effect of the recommendation on the size of the contract zone is less clear when $\alpha \neq \beta$. For example, suppose that $\alpha=0$ but $\beta>0$. In this case, an extreme high recommendation, $\mathrm{R}>\hat{x}_{s}$,

$\mathrm{B}$ (in a related bargaining experiment) to be slightly risk averse, with $\mathrm{c}_{\mathrm{b}}=-.23$ and $\mathrm{c}_{\mathrm{s}}=-.12$ ). Many of the results would be reversed if bargainers are risk-loving, but the laboratory data do not support a risk-loving hypothesis.

${ }^{7}$ It should be noted that if the recommendation has a larger influence on the seller than on the buyer (i.e. if $\beta>\alpha$ ), then a high recommendation increases the seller's final offer by more than the buyer's. In this case, the weight the arbitrator puts on the midpoint between final offers actually shrinks, and the effect of uncertainty and risk aversion on certainty equivalents grows. Because of these offsetting effects of possibly lower weight from the arbitrator, it is not possible to say that certainty equivalents are always increasing in $\mathrm{R}$, even when final offers are. 
will actually increase the size of the contract zone, as it would make the seller's final offer $\left(x_{s}=\beta R+(1-\beta) \hat{x}_{s}\right)$ larger but have no effect on the buyer's final offer. The opposite will be true with an extreme low recommendations, $\mathrm{R}<\hat{x}_{b}$, when $\alpha>\beta=0$. This perverse effect of extreme recommendations can result if bargainer weights are specified more generally as $\alpha=\alpha(\mathrm{R})$, or $\beta=\beta(\mathrm{R})$, with $\alpha, \beta \in[0,1]$ and $\alpha^{\prime}<0, \beta^{\prime}>0$. This would reflect a self-serving bias in how bargainers view a suggestion, which may a desirable way to model focal points given the empirical support found for the self-serving bias in negotiations (see Babcock and Loewenstein, 1997). ${ }^{8}$ Though this is an intriguing theoretical possibility, our data do not support this hypothesis of a self-serving bias in focal point effects. ${ }^{9}$

To summarize, Dickinson and Hunnicutt (2005) highlight the two main effects that recommendations may have on bargaining. The first of these-the uncertainty effect of Farber and Katz (1979) — states that the reduction of outcome uncertainty that a suggestion brings will decrease $\Delta$ and make dispute more likely. ${ }^{10}$ Existing laboratory research confirms that reduced outcome uncertainty increases dispute rates (Ashenfelter et al., 1992; Babcock and Taylor, 1996). The focal point effect (see Schelling, 1957) suggests that, irrespective of the size of the contract zone, any recommendation is salient and should help coordinate negotiations and reduce

\footnotetext{
${ }^{8}$ An extreme suggestion typically increases the size of the contract zone when its effect on the party for whom it is favorable is larger than its effect on the other party. That is, an extremely high suggestion will mostly enlarge the contract zone if its effect on the seller (given by $\beta$ ) is larger than its effect on the buyer (given by $\alpha$ ).

${ }^{9}$ Specifically, neither extreme nor moderate suggestions are shown to increase the divergence between the seller and buyer final bargaining positions, which is what one would predict if bargainers have self-serving $\alpha, \beta$ weights as described above. This can be seen also in Figure 1, to be discussed in the Results section. The data also do not support the opposite case where less self-serving suggestions are more heavily weighted—one might argue this if focal point weights are affected by a type of Bayesian updating.

${ }^{10}$ This is a formal statement of how recommendations can actually damage prospects for voluntary settlement, as has been suggested "....., in order to preserve the uncertainty surrounding the arbitration process and to encourage real bargaining, allowing the arbitrator to act as a mediator and other mechanisms that provide flows of information from the arbitrator to the parties will be counterproductive." Farber and Katz (1979), p. 63 (emphasis added).
} 
dispute rates. The net effect of recommendations on bargaining outcomes is ultimately an empirical question. $^{11}$

In our framework, the focal point effect of a recommendation can not only directly reduce certainty by revealing a portion of the likely settlement outcome $(\gamma>0)$, but it also indirectly reduces uncertainty via the sophisticated arbitrator (i.e., by increasing the weight placed on the final bargaining positions). As a result, our framework provides a conservative test of the potential for recommendations to reduce dispute rates. The initial results in Dickinson and Hunnicutt (2005) indicate that the focal point effect likely dominates the uncertainty effect. However, many questions remained unanswered. Specifically, our theoretical approach to modeling final offers as a function of the recommendation generates additional hypotheses that are testable from the experimental data. Our previous work did not generate final offer data, which limited a previous exploration of final bargaining position effects. Also, the current experiments include a treatment (below) with a zero-weighted recommendation (i.e., $\gamma=0$ ). This provides a cleaner test of the degree to which inclusion of a suggestion can improve settlement rates, independent of the degree to which the suggestion is weighted at final impasse.

\section{Experimental Environment}

\footnotetext{
${ }^{11}$ The existing literature is not in complete agreement over the effect of uncertainty and contract zone size on dispute rates. While some argue that larger contract zones imply lower dispute rates (e.g., Crawford, 1982; Farber and Bazerman, 1987), others argue that larger contract zone imply that there is more over which to dispute, thereby increasing dispute rates (e.g., Tracy, 1986, 1987; Crampton, 1992). Our position is that if the uncertainty effect holds, lower dispute rates should follow from larger contract zones, ceteris paribus, which is consistent with results in Ashenfelter et al, 1992. If the focal point effect is important, dispute rates may fall independent of the size of the contract zone.
} 
We generate data from a controlled laboratory bargaining environment to empirically examine the effects of focal points and outcome uncertainty. The experiment uses a computer interface to randomly and anonymously match subjects—disputant $B$ (the buyer) and disputant $S$ (the seller) - with the same anonymous counterpart for twenty 3-minute rounds, with subjects bargaining over the value of a variable, $x .{ }^{12}$ Payoff information is private, but subjects are aware that counterpart earnings move opposite own-earnings. Thus, subjects are aware that their own gain is their counterpart's loss, and private payoff level information simulates the real world asymmetry that exists in assessing the value your bargaining counterpart places on the object of negotiations. Given this, our environment is one in which the exact size of the contract zone is uncertain. ${ }^{13}$ The disputants bargain in each round over a $\$ 2.00$ pie, which (unknown to the disputants) would be equally split at $x=500$. Dollar payoffs for disputant $B$ are decreasing in $\mathrm{x}$ and given by $\mathrm{P}_{\mathrm{B}}(\mathrm{x})=1.00+.005^{*}(500-\mathrm{x})$. For disputant $S$, payoffs are increasing in $\mathrm{x}$ and given by $\mathrm{P}_{\mathrm{S}}(\mathrm{x})=1.00+.005 *(\mathrm{x}-500)$. This private payoff information is presented to the subjects by means of payoff tables.

The experiment does not allow communication other than the numeric messages transmitted through the subjects' computer terminals. The bargaining environment is relatively unstructured. Offers can be exchanged freely, and there is no requirement that offers must "improve" upon previous offers, or that there be counteroffers, or that there be any offer at all.

\footnotetext{
${ }^{12}$ The experimental environment is motivated by the design of Ashenfelter et al (1992), and is an extension of the bargaining-with-arbitration application used in Dickinson (2004).

${ }^{13}$ Additionally, subjects may not make offers outside of their bargaining range. Disputant $A$ is instructed to bargain for $x$ between 200 and 700, and disputant $B$ for $x$ between 300 and 800 . The theoretical predictions are silent as to the effects of this detail, but it is meant to improve the validity of the data since real-world bargainers would likely not have full information on their counterpart's target range. Further, asymmetric ranges should help avoid the 5050 split focal point (an issue mentioned in Ashenfelter et al., 1992, though they deal with it in a different way).
} 
The most recent offer of either disputant is displayed at the top of the offer queue, and either disputant can accept his/her counterpart's standing offer at any time.

Subjects proceed at their own pace through on-screen instructions that explain in detail all aspects of the experimental bargaining environment. Sample bargaining screens are displayed to the subjects in the general instructions to highlight important details (instructions available at http://www.appstate.edu/ dickinsondl/instructions.html). Across all experiment groups we utilized eight different dispute resolution treatments: NA, NAsugg, CAnaive, CAsoph, CAsugg(0), CAsugg(.20), CAsugg(.50), and CAsugg(.80). Each particular experimental group participates in four distinct treatments (five rounds of each) over the course of a 20-round experiment. ${ }^{14}$ In the NA (No Arbitration) treatment subjects are allowed to bargain for the entire 3-minute round, and should they reach the end of the round without agreeing on the value of $x$, payoffs to both bargainers are zero. NAsugg is similar except that a nonbinding suggestion is given at 1.5 minutes into the round. CAnaive and CAsoph are conventional arbitration (CA) treatments that do not provide a suggestion, but rather let subjects bargain for the entire 3 minutes prior to implementing a settlement. This settlement is a draw from a $\mathrm{N}(500,60)$ distribution of potential arbitrator settlements. Subjects receive prior information on the computer "decision-maker" by viewing a table of 100 previous draws from the distribution in the instructions (see Ashenfelter et al, 1992, for the use and justification of this form of mechanizing the arbitrator for experimental purposes), along with viewing the density

\footnotetext{
${ }^{14}$ Subjects were unaware that 5 rounds of each treatment would be completed, which helps control for strategic play across multiple rounds. Also the specific ordering of the treatments varied for different bargaining pairs (although each treatment consisted of five consecutive rounds) - this was to control for potential ordering effects.
} 
function and being given information on central tendencies from the distribution. ${ }^{15}$ The CAnaive arbitrator implements a random draw from the arbitrator distribution as the binding settlement, whereas the CAsoph treatment weights the bargainers' final offers as per equation (1), though without a suggestion (i.e., $\gamma=0$ ).

The various CAsugg treatments implement settlements based on (1) (with $\gamma \geq 0$ ), and the number in parenthesis refers to the gamma-weighting of the suggestion. In these treatments, a suggestion was given at 1.5 minutes. In all treatments that give a suggestion, suggestions were given as draws from the same $\mathrm{N}(500,60)$ distribution as for the arbitrator, and subjects were given the same information on the computer "suggestor" distribution as they were given for the computer arbitrator. The use of the exact same distribution for both the suggestion and arbitrator settlement-preference distributions is externally valid in the sense that arbitrators, mediators, and fact-finders, often come from the same pool of neutral dispute resolution agents in the field. In all treatments subjects were allowed to submit final offers at impasse, and the binding settlement was only implemented if final offers were still in disagreement (i.e., $x_{\mathrm{b}}<x_{\mathrm{s}}$ ).

In utilizing an anonymous, no-communication experiment, we trade off some external validity for a higher level of internal control in our experiments. This approach is meant to address the main weakness of field data on negotiations and dispute settlement- - the lack of comparability of data across dispute resolution conditions. While the external validity of laboratory bargaining data may be a concern, there is precedence in the literature supporting the usefulness of experiments when subjects are economically motivated, as ours are (see Bolton and Katok, 1998; Roth et al., 1988). Finally, we must address certain data issues given that our

\footnotetext{
${ }^{15}$ This information given over-and-beyond the table of 100 previous draws was implemented to minimize optimism about likely outcomes from the experimental arbitrator (see Dickinson and Hunnicutt, 2005).
} 
subjects are matched as bargaining counterparts for the entire 20-round experiment. As a result, the econometric analysis of the data controls for potentially interdependent error terms for a given subject-pair across rounds, and it also controls for the bargaining history of the subject-pair to address the concern of subject-learning.

\section{Results}

We report results from 77 bargaining pairs, each completing a 20-round experiment. Subjects earned, on average, $\$ 20$ for participation in the 1.5 hour experiment. The main results are summarized in Tables 1 and 2, which analyze the determinants of dispute rates, final bargaining positions, and settlement outcomes. Though the computer application did not allow submission of offers outside one's suggested bargaining range, it did allow a bargainer to agree to an offer outside of the bargaining range. As such, a small number of observations are omitted from the analysis (40 out of 1540), leaving us with 1500 total rounds of bargaining data.

\subsection{Dispute Rates}

Dispute rates are often considered the most important factor in evaluating the effectiveness of an ADR procedure. Table 1 shows the results from a binomial probit model of dispute rates (dispute $=1,0$ otherwise). Here, we code dispute $=1$ when the bargaining pair utilizes the dispute resolution mechanism in a given round. If the pair is at impasse at the end of the round, but their final offers converge (or criss-cross, such that $x_{b}>X_{\mathrm{s}}$ ), then this is coded as a voluntary settlement (i.e., dispute $=0$ ). The model estimates treatment effects of the various dispute resolution procedures, as well as the effects of two bargaining experience variables, Round and Dispute History. The variable Round=1-20 measures the effect of the bargaining round, to control for learning or experience within the experiment. Dispute History=1-19, which is the cumulative previous number of disputes in which the bargainer pair has engaged, accounts 
for pair-specific bargaining history in the experiment. We report the estimated marginal effects in Table 1, and the covariance matrix is adjusted for data clustering by bargaining pair. The model correctly predicts $77 \%$ of the dispute outcomes.

In reviewing the treatment variable marginal effects it is clear that the use of arbitration significantly increases the likelihood of dispute relative to the NA treatments (the omitted treatment variable category is NA. This is not surprising giving that arbitration reduces the direct monetary cost of dispute. Relative to the naïve arbitrator treatment (CAnaive), CAsoph increases the likelihood of dispute by a statistically insignificant amount (Wald test of the two coefficients, $\mathrm{p}=.47$ ), though in the direction predicted by our theoretical analysis of contract zone size — contract zones are smaller with the sophisticated arbitrator, which should imply higher dispute rates. In comparing the suggestion treatments, the pattern of the estimated marginal effects indicates a peak in the marginal increase in dispute rate probability at CAsugg(.50). The coefficient on CAsugg(.50) is significantly larger than the coefficient on $\operatorname{CAsugg}(0)(\mathrm{p}=.06$ for the Wald test) and the coefficient on the other extreme, CAsugg $(.80)(\mathrm{p}=.01){ }^{16}$

In comparing arbitration with a recommendation versus without, recall that $C A \operatorname{sugg}(0)$ is identical to CAsoph, except that $\mathrm{CAsugg}(0)$ includes a midround suggestion. Furthermore, in CAsugg $(0)$ the recommendation is completely ignored in arbitration, and so there is no direct

\footnotetext{
${ }^{16}$ Interestingly enough, this pattern of coefficients indicates that, relative to NA, the effect of CAsugg as a function of, $\gamma$, is an inverted $\mathrm{U}$-shape. In other words, the highest dispute rates are predicted when $\gamma=.50$, and the lowest when $\gamma=0$ and $\gamma=1.00--$ this is close to the $\gamma=.80$ treatment we implement. Though these predictions are not consistent with the theoretical predictions of a contract zone with a known suggestion, they may be consistent with the predictions of a prior or ex ante contract zone, $\Delta_{\mathrm{ea}}$, which can be derived in the case that bargainers have yet to receive the suggestion (but have a distributional expectation of what the suggestion would be). In the ex ante case, Dickinson and Hunnicutt (2005) derive $\Delta_{\mathrm{ea}}$ for the naïve arbitrator case, and the size of $\Delta_{\mathrm{ea}}$ as a function of $\gamma$ is Ushaped. If a smaller contract zone leads to higher dispute rates, then this implies the highest dispute rates at $\gamma=.50$, consistent with the present data. If subjects have prior beliefs of $\Delta$, then posterior estimates of the contract zone, $\Delta_{\text {post }}$ - calculated post-suggestion - may fail to accurately predict dispute rates if subjects are not perfect Bayesian updaters. Data in Grether (1980) indicate that subjects overweight prior information in updating their beliefs.
} 
uncertainty effect altering the size of the contract zone through the parameter $\gamma$. However, due to our modeling of the sophisticated arbitrator, if the suggestion is focal and causes final offers to converge, then this indirectly shrinks the contract zone due to the arbitrator placing a higher weight on the midpoint of the more convergent final offers. This indirect effect of suggestions on the contract zone makes the comparison of CAsoph and CAsugg(0) a relatively strong test of the effectiveness of suggestions. The marginal effect on CAsoph is significantly larger than the marginal effect on CAsugg(0) (Wald test, $\mathrm{p}=.06$ ). A nonbinding suggestion also lowers dispute rates in the NA treatment, although the effect here is not statistically significant. In sum, our data provide evidence that suggestions prior to the use of a binding settlement procedure can significantly increase settlement rates, which is a key result of our paper.

Our results also indicate that when suggestions are used, settlement rates are highest when the suggestion is either weighted little or much. There is no significant difference in the coefficients on CAsugg( $(0)$ and CAsugg(.80) (Wald test $\mathrm{p}=.27$ ), but the significantly larger marginal effect on CAsugg(.50) indicates that subjects are more likely to dispute in this treatment compared to other CAsugg treatments. While this is speculation, subjects may view CAsugg(.50) as the least risky of the CAsugg treatments because both the suggestion and the arbitrator settlement preference will be equally weighted in the final settlement decision (see also footnote 18). Risk-averse subjects will dispute more when the risk of doing so is least. In essence, risk is most diversified when bargainers can still anticipate two equally-weighted draws from the arbitration/suggestion distribution (versus unequally weighted draws). Results not only show that dispute rates are highest in $\operatorname{CAsugg}(.50)$ (Table 1), but results on settlement timing (full results available on request) show that after one minute, the cumulative settlement frequency is lowest in CAsugg(.50) compared to all other CAsugg treatments. This is roughly 
consistent with the notion that risk-averse bargainers want to avoid risk and choose to settle more quickly when a recommendation is weighted on one extreme or another.

Finally, the Table 1 results also identify bargaining experience effects in Round and Dispute History. Disputes are less likely the higher the round number, but more likely with each previous round of dispute history for the pair. This result highlights the distinct effects of good versus bad history on dispute rates.

\subsection{Bargaining positions and Settlement Values}

The first two columns of Table 2 show the results of a model of buyer and seller final bargaining positions. Final offers generated at impasse are a measure of theoretical final offers, but the experimental bargaining program does not collect "final offer" data when agreement occurs prior to the end of the round. For this reason, we code the final bargaining position to equal the final offer, when given at the end of the round, or the agreement $x$-value in the event that the subjects do not reach the end of the round.

Our theoretical model yields testable predictions in terms of the effects of a recommendation on final bargaining positions and settlement $\mathrm{x}$-values. We therefore estimate three models in Table 2: Buyer and Seller final bargaining positions, and agreement x-value. For the model of agreement $\mathrm{x}$-values, we restrict our attention to the subset of rounds in which a voluntary settlement occurred ( $\mathrm{N}=1038)$, and we correct for sample selection for that model using the two-stage Heckit procedure.

The independent variables in Table 2 are mostly similar to those in Table 1 . One important distinction is in the use of variables to identify the impact of the specific suggestion on final bargaining positions. Past Mid-round and Suggestion Exists are dummy variables that equal one when bargainers make it past 90 seconds and receive a suggestion, respectively. 
Suggestion Value measures the effect of the specific suggestion on bargaining positions and settlement values, with a squared term included to allow for nonlinear effects.

Another main result is that final bargaining positions and settlement (agreement) $\mathrm{x}$-values are all positively related to suggestions. The pattern of coefficient estimates indicate a relationship shown in Figure 1-for the range of suggestions in our experiments, the data lie on the upward sloping portion of the estimated quadratic relationship. This result is consistent with our modeling of focal suggestions on bargaining positions. The fact that focal suggestions alter the location of the contract zone generates the prediction that agreement $\mathrm{x}$-values would be positively related to suggestions, as is estimated in Table 2 .

In the buyer and seller equations in Table 2, there is some evidence that final bargaining positions are more divergent in CAnaive and CAsoph than in the CAsugg treatments, due mainly to the buyer (Player A). ${ }^{17}$ The coefficient on Suggestion Exists may appear to weaken this result because buyers significantly lower their final bargaining positions whenever a suggestion exists, but one must also consider the effects of the level of the suggestion. When suggestions are used Figure 1 indicates a slight convergence trend for higher suggested $\mathrm{X}$-values, although the trend is statistically insignificant.

An alternative approach to evaluation of this result is to examine the variance of arbitrated outcomes in the CAsugg treatments. This is appropriate because more convergent final bargaining positions imply a higher weight to be placed by the sophisticated arbitrator on the bargainers' final positions, which would reduce the variability of the arbitrated settlements.

\footnotetext{
${ }^{17}$ Given that we use data from all voluntary settlement rounds and disputed rounds, our coding of final bargaining positions in the voluntary settlement rounds necessarily implies convergent final bargaining positions, which may seem to bias our Table 2 results towards convergent final positions in CAsugg treatments due to their higher settlement rates. The results are, however, unchanged if one considers only the subsample of data where the outcome is dispute.
} 
Even if negotiations fail, bargainers retain some control over the arbitrated settlement when the arbitrator considers the proximity of the final bargaining offers in making a final decision. So, the Table 2 results may imply a larger variance of arbitration settlements when there is no suggestion. Table 3 shows summary statistics on each arbitration treatment. Except for CAsugg(.50), the arbitration settlement variance is lower in the CAsugg treatments. This is an important secondary result, because a smaller variance of arbitrated settlements may be important for the procedure to be considered acceptable (see Farber, 1980). In sum, because of the sophisticated arbitrator, not only do recommendations lower dispute rates (Table 1), but in most cases they also reduce the variance of arbitration settlements by drawing offers together (Tables 2 and 3). Finally, the estimated coefficients on Round and Dispute History are consistent with the Table 1 results. They indicate that round experience brings bargainers together, while dispute history does the opposite. In fact, one round of bad history (i.e., dispute) offsets the positive effects of over two rounds of general bargaining experience as measured by Round. The Agreement $x$-value model in Table 2 also indicates that certain ADR treatments significantly increase settlement values. The pattern of coefficients here is consistent with the hypothesis that the average buyer is more risk-averse than the average seller in our data. Subjects in our experiment responded to a hypothetical lottery question meant to elicit risk preferences. However, we do not consider their responses an accurate enough measure of risk preferences to include the variable in our formal analysis—subjects exhibited some confusion over the presentation of the lottery question—-but average responses do indicate a slightly more risk-averse average buyer than seller. Buyers would then give away more to sellers in negotiated settlements when the ADR procedure is considered riskier, which may be the case with extreme weighted suggestions in the CAsugg treatments (see footnote 18). The predicted settlement 
values shown in Figure 1 are closer to predicted seller final bargaining positions than buyer final bargaining positions, which is also consistent with sellers being less risk averse than buyers. In

short, these treatment effect results from the Agreement $\mathrm{x}$-value model in Table 2 are suggestive of bargaining power differences in our data, but a more detailed analysis can only be conducted with an experimental design that generates better measures of risk preferences.

\section{Conclusion}

Dispute resolution procedures are intended to improve voluntary settlement rates, and nonbinding procedures generally boast high settlement rates. However, it is unclear from field data whether nonbinding procedures generate higher settlement rates for comparable disputes because binding procedures are often reserved for the most difficult disputes. A hybrid procedure might include a nonbinding procedure followed by a binding procedure if needed, and this paper has examined the effectiveness of implementing a nonbinding suggestion prior to binding dispute settlement. Such a procedure reflects important characteristics of real world dispute resolution, such as the use of a nonbinding recommendation prior to an arbitrated labor contract settlement, the use of parental input prior to resolving a sibling dispute, or the use of court-annexed mediation prior to a legal dispute proceeding to trial.

Theoretically, we analyze a model of sophisticated arbitrator decision-making that identifies the effects of recommendations on the bargaining contract zone. Our laboratory data support the testable hypotheses of our theoretical framework, and support the use of nonbinding ADR mechanisms that use recommendations. Dispute rates are significantly lower when a recommendation stage is included prior to arbitration. The most effective procedures at reducing dispute rates are those that weight recommendations by a lot or a little in determining final binding voluntary settlement outcomes are positively related to suggestions. We do not further 
explore in this paper the mechanism by which recommendations may serve as focal points, but existing research has made progress in this area (see, for example, Janssen, 2001; Bacharach and Bernasconi, 1997; and Sugden, 1995).

Consistent with our theoretical analysis, final bargaining positions and voluntary settlement values are positively related to recommendations. Because recommendations generally cause final bargaining positions to converge, bargainers also retain more control over the outcome of an arbitrated settlement under our theoretical framework, and in our empirical results. This is likely an important additional consideration in improving the acceptability of binding settlement outcomes, because procedures that generate highly variable arbitrated outcomes are not likely to be considered acceptable by disputants (Farber, 1980).

The implications of this research are significant given the large sums of dollars in dispute is a variety of industries. Improved dispute resolution procedures can more efficiently allocate these disputed amounts by increasing settlement rates, because voluntary settlements imply selfdetermined outcomes by the bargainers. There are also many informal settings in which nonbinding suggestions prior to mandated outcomes can lower dispute rates. Long-term relationships are likely to be healthier when dispute rates are low among bargainers who repeatedly interact. This research highlights the benefits that recommendations can have on improving bargaining outcomes, and these recommendations can be a simple amendment to any binding dispute resolution procedures. 


\section{REFERENCES}

Ashenfelter, Orley, Janet Currie, Henry S. Farber, and Matthew Spiegel "An experimental comparison of dispute rates in alternative arbitration systems." Econometrica, 1992, 60(6), pp. 1407-1433.

Babcock, Linda, and Lowell J. Taylor "The role of arbitrator uncertainty in negotiation impasses." Industrial Relations, 1996, 35(4): 604-10.

Babcock, Linda., and George Loewenstein. 1997. "Explaining bargaining impasse: The role of self-serving biases.” Journal of Economic Perspectives, Vol. 11, No. 1, pp. 109-26.

Bacharach, Michael and Michele Bernasconi 1997. "The Variable Frame Theory of Focal Points: An Experimental Study." Games and Economic Behavior 19: 1-45.

Bolton, Gary E. and Elena Katok 'Reinterpreting arbitration's narcotic effect: An experimental study of learning in repeated bargaining." Games and Economic Behavior, 1998, 25:1-33.

Crampton, Peter "Strategic delay in bargaining with two-sided uncertainty." Review of Economic Studies, 1992, 59, pp. 205-225.

Crawford, Vincent "A theory of disagreement in bargaining." Econometrica, 1982, 50(3): 607637.

Dickinson, David L. “A Comparison of Conventional, Final-Offer, and 'Combined' Arbitration for Dispute Resolution" 2004, Industrial and Labor Relations Review, 57(2): 288-301.

Dickinson, David L., and Lynn Hunnicutt "Does Fact-Finding Promote Settlement? Theory and a Test." Economic Inquiry, 2005, 43(2): 401-416.

Dickinson, David L. "The Effects of Beliefs versus Risk Preferences on Bargaining Outcomes." 2005. Working paper, Appalachian State University.

Farber, Henry S. "An analysis of final-offer arbitration." The Journal of Conflict Resolution, December 1980, 24(4), pp. 683-705.

Farber, Henry S. "Splitting-the-difference in Interest Arbitration." Industrial and Labor Relations Review, 2001, 35(1): 70-77.

Farber, Henry S., and Max H. Bazerman, "Why is there disagreement in bargaining?" American Economic Review, 1987, 77(2):347-352. 
Farber, Henry S., and Harry C. Katz "Interest arbitration, outcomes, and the incentive to bargain." Industrial and Labor Relations Review, 1979, 33(1): 55-63.

Grether, David M. "Bayes Rule as a Descriptive Model: The Representativeness Heuristic." The Quarterly Journal of Economics, 1980, 95(3): 537-557.

Hebdon, Robert "Fact-Finding effectiveness: Evidence from New York state." Industrial Relations, 2001, 40(1). 73-82.

Holt, Charles A., and Susan K. Laury. 2002. "Risk aversion and incentive effects." American Economic Review, 92(5): 1644-55.

Janssen, Maarten C.W. 2001. "Rationalizing Focal Points." Theory and Decision 50: 119-148.

Roth, Alvin E., and J. Keith Murnighan, and Francoise Schoumaker "The Deadline Effect in Bargaining: Some Experimental Evidence.” American Economic Review, 1988, 78(4): 806-823.

Schelling, Thomas C. "Bargaining, Communication and Limited War" Journal of Conflict Resolution, 1957, 1:19-36.

Schotter, Andrew. 2003. "Decision Making with Naïve Advice." American Economic Review, 93(2): 196-201.

Schotter, Andrew., and Barry Sopher. 2002. "Advice and Behavior in Intergenerational Ultimatum Games: An Experimental Approach.” Mimeo, New York University.

Sugden, Robert. 1995. "A Theory of Focal Points" The Economic Journal 105:533-550.

Tracy, Joseph "An investigation into the determinants of U.S. strike activity." American Economic Review, 1986, 76, pp. 423-436.

Tracy, Joseph “An empirical test of an asymmetric information model of strikes." Journal of Labor Economics, 1987, 5, p. 149-173. 
TABLE 1

Probit Model (MLE estimates)

Dependent Variable $=$ Dispute

(marginal effects reported)

\begin{tabular}{cc}
\hline Independent Variable & Marginal Effect (p-value) \\
\hline Constant & $-.351(.00)^{* * *}$ \\
NAsugg & $-.06(.37)$ \\
CAnaive & $.46(.00)^{* * *}$ \\
CAsoph & $.50(.00)^{* * *}$ \\
CAsugg(0) & $.41(.00)^{* * *}$ \\
CAsugg $(.20)$ & $.42(.00)^{* * *}$ \\
CAsugg $(.50)$ & $.50(.00)^{* * *}$ \\
CAsugg(.80) & $.35(.00)^{* * *}$ \\
Round & $-.03(.00)^{* * *}$ \\
Dispute History & $.07(.00)^{* * *}$ \\
\hline
\end{tabular}

Model correctly predicts

$N=1500 \quad 1160 / 1500(77 \%)$ of outcomes

$*, * *, * * *$ indicates significance at the $.10, .05$, or .01 level, respectively, for the two-tailed test.

The covariance matrix is adjusted for data clustering by bargaining pair. 
TABLE 2

(OLS Estimates)

\begin{tabular}{|c|c|c|c|}
\hline Variable & $\begin{array}{c}\text { Dependent Variable= } \\
\text { Buyer Final } \\
\text { Bargaining Position } \\
\text { p-value in parenthesis }\end{array}$ & $\begin{array}{c}\text { Dependent Variable= } \\
\text { Seller Final } \\
\text { Bargaining Position } \\
\text { p-value in parenthesis }\end{array}$ & $\begin{array}{c}\text { Dependent Variable= } \\
\text { Agreement } \mathbf{x} \text {-value } \\
\text { p-value in parenthesis } \\
\text { (corrected for sample } \\
\text { selection }\end{array}$ \\
\hline Constant & $456.79(.00)^{* * *}$ & $421.00(.00)^{* * *}$ & $449.78(.00)^{* * *}$ \\
\hline Past Mid-round & $-27.63(.01)^{* * *}$ & $40.41(.00)^{* * *}$ & $7.67(.25)$ \\
\hline Suggestion exists & $-30.84(.09)^{*}$ & $-24.19(.20)$ & $-24.53(.11)$ \\
\hline Suggestion value & $-.046(.12)$ & $-.038(.19)$ & $-.038(.00)^{* * *}$ \\
\hline Suggestion value-squared & $.00025(.00)^{* * *}$ & $.00022(.00)^{* * *}$ & $.00022(.00) * * *$ \\
\hline NAsugg & $19.16(.47)$ & $30.75(.20)$ & $25.87(.07)^{*}$ \\
\hline CAnaive & $-57.09(.00) * * *$ & $51.20(.01)^{* * *}$ & $17.64(.30)$ \\
\hline CAsoph & $-46.87(.00) * * *$ & $63.65(.00)^{* * *}$ & $44.55(.01)^{* * *}$ \\
\hline CAsugg(0) & $4.03(.88)$ & $65.64(.01)^{* * *}$ & $54.17(.00)^{* * *}$ \\
\hline CAsugg(.20) & $3.72(.91)$ & $59.57(.04)^{* *}$ & $44.86(.02)^{* *}$ \\
\hline CAsugg(.50) & $-42.33(.13)$ & $55.16(.04) * *$ & $34.20(.11)$ \\
\hline CAsugg(.80) & $11.52(.70)$ & $68.95(.02)^{* *}$ & $54.60(.00)^{* * *}$ \\
\hline Round & $2.85(.00)^{* * *}$ & $-1.76(.04)^{* *}$ & $-.97(.41)$ \\
\hline Dispute History & $-6.60(.01)^{* * *}$ & $8.89(.00)^{* * *}$ & $5.51(.02)^{* *}$ \\
\hline \multirow[t]{2}{*}{ Lambda } & --- & --- & $-43.16(.12)$ \\
\hline & $\begin{array}{l}\quad N=1500 \\
\text { Adjusted } R^{2}=.11\end{array}$ & $\begin{array}{l}\quad N=1500 \\
\text { Adjusted } R^{2}=.18\end{array}$ & $\begin{array}{l}\quad N=1038 \\
\text { Adjusted } R^{2}=.05\end{array}$ \\
\hline \multicolumn{4}{|c|}{$\begin{array}{l}*, * *, * * * \text { indicates significance at the } .10, .05 \text {, or } .01 \text { level, respectively, } \\
\text { for the two-tailed test. }\end{array}$} \\
\hline
\end{tabular}




\section{Table 3}

Mean and variance of arbitrated outcomes by treatment

\begin{tabular}{cccc}
\hline \hline & $\begin{array}{c}\text { Average Dispute } \\
\text { Rate }\end{array}$ & $\begin{array}{c}\text { Mean of arbitrated } \\
\text { settlements }\end{array}$ & $\begin{array}{c}\text { Variance of arbitrated } \\
\text { settlements }\end{array}$ \\
\hline $\begin{array}{c}\text { CA Naïve } \\
(\mathrm{N}=100)\end{array}$ & 0.40 & 504.41 & 3264.21 \\
CA Sophisticated \\
$(\mathrm{N}=100)$ \\
CA sugg(0) \\
$\begin{array}{c}(\mathrm{N}=284) \\
\text { CA sugg(20) } \\
(\mathrm{N}=100) \\
\mathbf{C A} \text { sugg(50) } \\
(\mathrm{N}=184) \\
\mathbf{C A ~ s u g g ( 8 0 )} \\
(\mathrm{N}=100)\end{array}$ & 0.50 & 498.68 & 2746.59 \\
& 0.36 & 494.93 & 2465.79 \\
& 0.42 & 500.95 & 1627.72 \\
& 0.43 & 481.53 & 3546.93 \\
& 0.37 & 495.88 & 1577.88
\end{tabular}




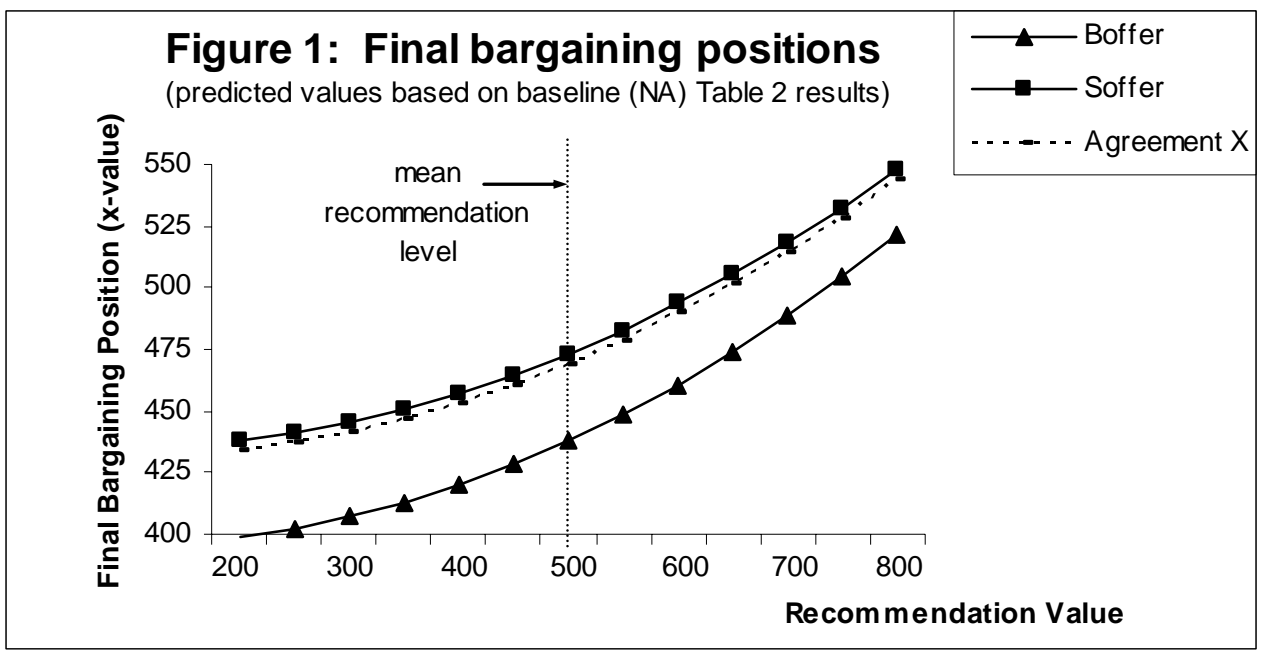

